\title{
DO COLONIALISMO À COLONIALIDADE: expropriação territorial na periferia do capitalismo
}

\author{
Wendell Ficher Teixeira Assis *
}

\begin{abstract}
O artigo ancora-se nas formulações de autores latino-americanos aglutinados no paradigma modernidade-colonialidade, para sugerir que os processos de expansão territorial foram e continuam sendo nodais para a lógica capitalista. Se, no colonialismo histórico, a rapina dos recursos naturais legitimava-se pela força e supremacia político-militar do Estado colonizador, no contexto atual, vigem outros mecanismos de poder que garantem a continuidade da expropriação. Para elucidar esse processo, formula-se a noção de colonialidade na apropriação da natureza, entendida como resultado da construção, no interior da modernidade, de formas econômico-instrumentais de se pensar e explorar o meio ambiente. Por fim, retomam-se as discussões sobre a pertinência da teoria da dependência e, com base em dados empíricos, sugere-se a emergência de novas relações centro-periferia, que estariam se estruturando por intermédio dos frequentes deslocamentos de capitais e pelo modo como grandes corporações transnacionais impõem novas formas organizativas de exploração do trabalho e da natureza.

Palavras-chave: Colonialidade. Colonialismo. Centro-periferia. Expropriação territorial. Teoria da dependência.
\end{abstract}

Los europeos piensan que solo lo que inventa Europa es bueno para el universo mundo y todo lo que sea distinto Frase atribuída a Simon Bolívar por Gabriel execrable. quez em El General en su Laberinto, 1989.

\section{INTRODUÇÃO}

Os estudos denominados pós-coloniais, subalternos ou pós-ocidentais, realizados na África, Ásia e América Latina, entendidos não somente como espaços geográficos, mas como lugares que ativam o pensamento crítico emancipador, vêm articulando uma perspectiva que evidencia a faceta colonial da expansão capitalista e de seu projeto cultural (Cajigas-Rotundo, 2007). Nessa mirada, as Américas não foram incorporadas dentro de uma já existente economia mundial capitalista; pelo contrário, não haveria uma economia capitalista mundial sem a existência das Américas (Quijano; Wal-

\footnotetext{
* Doutor em Planejamento Urbano e Regional. Professor Adjunto da Universidade Federal de Alagoas e pesquisador do Instituto de Pesquisa e Planejamento Urbano e Regional - IPPUR/UFRJ.

Campus A.C. Simões Av. Lourival de Melo Mota, s/n. Cidade Universitária. Cep: 57072970. Maceió - Alagoas - Brasil.wwficher@yahoo.com.br
}

lerstein, 1992). Quijano (2005) argumenta que esse processo começou com uma colonização interna de povos com identidades diferentes, mas que habitavam os mesmos territórios e foram convertidos em espaços de dominação interna. Esse fenômeno se desdobrou com a colonização imperial ou externa de povos que não só tinham identidades diferentes, como habitavam em territórios para além do espaço de dominação interna dos colonizadores.

A expansão colonial iniciada no século XVI, com as grandes navegações e o "descobrimento" das Américas - posteriormente incrementada com o neocolonialismo do final do século XIX, que promoveu a repartição da África e Ásia -, é vista, nessa abordagem, como condição sine qua non para a existência e a manutenção do capitalismo industrial. Por outro lado, a extinção do colonialismo histórico-político nas Américas, com a construção de nações independentes no século XIX, bem como na África e Ásia, por intermédio da descolonização em meados do século XX, não foi condição necessária e suficiente para a emancipação político-econômica e cultural dos países periféricos. Assim, a acumulação primitiva 
colonial, longe de ser uma pré-condição do desenvolvimento capitalista, foi um elemento indispensável da sua dinâmica interna e posterior continuidade (Coronil, 2000). A esse respeito, Lander (2006, p. 250) destaca que:

\begin{abstract}
Ao fazer abstração da natureza dos recursos, espaço e territórios, o desenvolvimento histórico da sociedade moderna e do capitalismo aparece como um processo interno, autogerado, da sociedade europeia, que posteriormente se expande para as regiões atrasadas. Nessa construção eurocêntrica desaparece do campo de visão o colonialismo como dimensão constitutiva destas experiências históricas.
\end{abstract}

Para elucidar os desdobramentos sociopolíticos desse processo, Quijano (1997) cunhou o conceito de colonialidade como algo que transcende as particularidades do colonialismo histórico e que não desaparece com a independência ou descolonização. Essa formulação é uma tentativa de explicar a modernidade como um processo intrinsecamente vinculado à experiência colonial. Essa distinção entre colonialidade e colonialismo permite, portanto, explicar a continuidade das formas coloniais de dominação, mesmo após o fim das administrações coloniais, além de demonstrar que essas estruturas de poder e subordinação passaram a ser reproduzidas pelos mecanismos do sistema-mundo capitalista colonial-moderno. Dessa maneira, a noção de colonialidade atrela o processo de colonização das Américas ฮ̀ं à constituição da economia-mundo capitalista, concebendo ambos como partes integrantes de um mesmo processo histórico iniciado no século XVI (Castro-Gomez; Gosfroguel, 2007).

A construção das hierarquias raciais, de gênero e de modos de apropriação dos recursos naturais, pode ser vista como simultânea e contemporânea à constituição de uma divisão internacional do trabalho e dos territórios, marcada por relações assimétricas entre economias cêntricas e periféricas. Na perspectiva I da colonialidade, as antigas hierarquias coloniais, que foram agrupadas na relação europeu versus não europeu, continuaram arraigadas e enredadas na divisão internacional do trabalho e na acumulação do capital à escala global. ${ }^{1} \mathrm{O}$ mesmo poderia ser dito do estabelecimento de relações sociais cujo modo operativo favorece tanto a constituição quanto a perpetuação da existência de sujeitos subalternizados nas esferas intra e interestatais. ${ }^{2}$

Essa matriz de poder, que se expressa por meio da colonialidade, procurava e ainda procura encobrir o fato de que a Europa foi produzida a partir da exploração político-econômica das colônias. Não há como desconsiderar as implicações históricas do estabelecimento desse padrão de dominação, que se reflete na recíproca produção histórica da América e da Europa, como redes de dependência histórico-estrutural (Quijano, 2005). Entretanto, o caráter constitutivo da experiência colonial e da colonialidade não tem figurado nas abordagens hegemônicas e eurocêntricas, inclusive de intelectuais latinos, que desprezam a importância que as relações intercontinentais tiveram para a emergência do capitalismo. Ao lançar luz sobre o lado obscuro da modernidade, o paradigma colonialidade-modernidade clarifica que os diferentes discursos históricos

${ }^{1} \mathrm{Na}$ tentativa de entender as estratégias de poder subjacentes ao exercício da colonialidade, Quijano $(1997 ; 2005$ 2010) desenvolveu a ideia de colonialidade do poder, como um modelo de exercício da dominação especificamente moderno que interliga a formação racial, o controle do trabalho, o Estado e a produção de conhecimento. Em outras palavras, a colonialidade do poder é a classificação social da população mundial ancorada na noção de raça, que tem origem no caráter colonial, mas já provou ser mais duradoura e estável que o colonialismo histórico, em cuja matriz foi estabelecida (Quijano, 2000). Para Castro-Gomez (2007), esse conceito amplia a ideia foucaultiana do poder disciplinário, ao mostrar que os dispositivos panópticos construídos pelo Estado moderno se expandem a uma estrutura mais ampla e de caráter mundial, configurada pela relação colonial entre Estados cêntricos e periféricos.

${ }^{2}$ Nessa direção, Guha (1997) sustenta que subalternidade não é somente uma questão de subordinação de classe dentro de um país industrial, mas de subordinação de organizações sociais e históricas no interior de estruturas interestatais, como as que se estabeleceram entre Índia e Inglaterra. Para o autor, o colonialismo britânico se caracterizou pelo exercício de uma dominação sem hegemonia, uma composição seriamente determinada pela dissolução dos elementos de persuasão e cooperação, que se ancoravam na força despótica da superioridade ocidental para erigir uma dominação política que aniquila o surgimento do dissenso ou conflito. Por outro lado, se poderia argumentar que as estratégias de colonização portuguesa e espanhola nas Américas parecem sugerir outro itinerário, que contemplaria uma fase do uso da força, com aniquilamento dos diferentes, alinhavada, em seguida, por processos de persuasão e cooperação que possibilitaram a construção de uma dominação hegemônica. 
(evangelização, civilização, modernização, desenvolvimento e globalização) procuram sustentar a concepção arbitrária de que há um padrão civilizatório que é, simultaneamente, superior e normal (Lander, 2000). No receituário clássico da modernidade, bem como nos desdobramentos hodiernos do capitalismo, duas alternativas infernais (Stengers; Pignarre, 2005) têm sido infligidas aos povos subalternizados: uma decorre da completa aniquilação e a outra, da civilização imposta.

Inspirado por essa abordagem teóricometodológica o artigo procurará demonstrar a continuidade dos processos de expropriação de recursos naturais localizados em países da periferia do capitalismo, que, embora não sejam mais alvo do domínio político-administrativo dos colonizadores, ainda funcionam como espaço de avanço das frentes de acumulação do capital. Para cumprir tal tarefa, primeiramente, avançará na elaboração da ideia de que tem vigorado, no sistema-mundo moderno-colonial, uma atitude utilitarista no tocante à exploração das riquezas naturais, consubstanciada por aquilo que aqui se denomina colonialidade na apropriação da natureza. Na sequencia, associará a perpetuação desse modelo agro-minero-exportador à continuidade de relações de dependência, que, no entanto, vem se configurando de outra maneira, dadas as especificidades do capitalismo contemporâneo. Por fim, retomará as contribuições da Teoria da Dependência, sobretudo a vertente avançada por (Cardoso; Faletto, 1970) procurando expor uma reconceituação dos processos que engendram e reatualizam relações de subserviência político-econômica.

\section{COLONIALIDADE NA APROPRIA- ÇÃO DA NATUREZA: as novas formas de uma velha exploração territorial}

Como se procurou sugerir na sessão anterior, há variadas formas de expressão e exercício da colonialidade. Assim, a colonialida- de do poder se refere à inter-relação entre as formas modernas de exploração e dominação e o processo europeu de expansão colonial. A colonialidade do saber se relaciona com a epistemologia e suas formas de reprodução de regimes de pensamento, enquanto a colonialidade do ser se refere à experiência vivida de colonização e seus impactos na linguagem e na visão de mundo dos povos colonizados (Maldonado-Torres, 2007). Embora o paradigma modernidade-colonialidade tenha logrado avançar nessas diferentes frentes, Escobar (2003) assevera que, no interior dessa corrente de pensamento, há três áreas de grande importância que têm permanecido sem uma adequada discussão, a saber: as relações de gênero, uma abordagem da apropriação da natureza e do meio ambiente, e, por ultimo, mas não menos importante, a necessidade de se construir imaginários econômicos capazes de ancorar lutas concretas contra o neoliberalismo.

A partir das trilhas já abertas pelo paradigma modernidade-colonialidade, se procurará compreender a inserção de novos territórios nos circuitos de acumulação do capital como expressão de uma das lógicas da colonialidade. Para isso, se lançará mão da ideia de que há uma colonialidade na apropriação da natureza, entendida tanto como resultado da construção no interior da modernidade de formas econômico-instrumentais de se pensar e explorar o meio ambiente, quanto como expressão de processos concretos de expropriação territorial que sustentam a lógica prevalecente da acumulação capitalista e mantém em funcionamento o sistema-mundo colonialmoderno. A colonialidade na apropriação da natureza se refere, portanto, à existência de formas hegemônicas de se conceber e extrair recursos naturais considerando-os como mercadorias, ao mesmo tempo em que representa o aniquilamento de modos subalternos de convívio com o meio ambiente, bem como a perpetuação e justificação de formas assimétricas de poder no tocante à apropriação dos territórios. 
Se, no colonialismo histórico, a rapina dos recursos naturais se legitimava pela força e supremacia político-militar do Estado colonizador, no contexto de colonialidade na apropriação da natureza, há outros mecanismos de poder que promovem a aceitabilidade da exploração territorial, dentre os quais se destacam: consideração, como vantagem comparativa no mercado mundial, a extração de riquezas naturais; discurso da disponibilidade de terras vazias, degradadas e inexploradas; necessidade de tornar o território economicamente produtivo; criação da ideia-força de que o progresso e o crescimento econômico se atrelam à extração de riquezas naturais; conciliação e harmonia entre exploração capitalista da natureza e preservação ambiental; e integração dos produtos primários à economia global como forma de pavimentar o caminho para era moderna. ${ }^{3}$ Dito em outros termos, durante o período do colonialismo histórico, a exploração de bens primários foi levada a cabo através da mão visível da dominação política; agora está organizada por mecanismos de poder operados pela aparente mão invisível do mercado em associação com a destacada e necessária presença do Estado (Coronil, 2000).

Como foi visto anteriormente, a expansão territorial e a dominação político-econômica das colônias foi condição indispensável

${ }^{3}$ Sobre esse aspecto, é elucidador o pronunciamento do ช Presidente Lula realizado durante a cerimônia de encer๑ ramento do Seminário Empresarial Brasil - Zâmbia, ocorrido em julho de 2010, em Lusaka: "Olhando o mapa do $\circlearrowleft$ mundo, onde a gente percebe que tem terra? É no conti-

$\sim$ nente africano e no continente latino-americano onde tem

ปิ terra, onde tem sol e onde tem água e, portanto, nós temos

๓ que fazer disso uma vantagem comparativa na nova for-

$\checkmark$ ma de investimento e de produção no século XXI. Queria

$\dot{2}$ dizer aos companheiros da Zâmbia que eu estou conven-

i cido, e vou repetir aqui uma coisa que eu tenho dito no

$\curvearrowright$ Brasil: que a savana africana tem as mesmas característi-

\& cas do cerrado brasileiro [...]. E a tecnologia e o manejo do

- solo transformaram o cerrado brasileiro no maior produtor

ลิ de grãos do mundo por hectare, em um grande produtor

$>$ de cana-de-açúcar, em um grande produtor de milho, em

si um grande produtor de soja, em um grande produtor de qualquer coisa que a gente queira produzir no cerrado brasileiro. E isso, inexoravelmente, acontecerá com a sa-

vana africana, inexoravelmente. [...] Eu acho que, por isso, nós depositamos tanta fé e tanta esperança no continente

africano e, sobretudo, levando em conta o potencial energético deste continente, não apenas pela quantidade de hidrelétricas que podem ser construídas aqui, financiadas por bancos brasileiros, construídas por empresas brasileiras. Não apenas por isso, mas pelo potencial da produção de etanol" (Silva, 2010). para o desenvolvimento do capitalismo. No cenário atual, prescindindo de uma dominação política de corte colonial que desconhece a soberania dos povos, as grandes corporações empresariais e os conglomerados financeiros têm se valido do poder econômico para expandir e incorporar novos espaços nos circuitos de acumulação do capital. Nesse sentido, o direcionamento de capitais para a produção brasileira de agrocombustíveis ${ }^{4}$ pode exemplificar a continuidade da incorporação de novos territórios na lógica de acumulação capitalista, além de evidenciar a vigência de uma colonialidade na apropriação da natureza, tendo em vista que os recursos naturais são vistos como vantagem comparativa capaz de garantir a integração à economia global. Entre 2004 e 2009, período que coincide com os anúncios da União Europeia e dos Estados Unidos de substituição de combustíveis fósseis, a produção sucroalcooleira nacional atraiu mais de US $\$ 6,3$ bilhões de dólares em investimentos estrangeiro direto, e isso representou $5,4 \%$ de todos os investimentos estrangeiros diretos aplicados em todo o mercado brasileiro. Desse montante, US\$ 4 bilhões e 337 milhões, ou o equivalente a $68,2 \%$, foram direcionados exclusivamente para a fabricação de agrocombustíveis (BC/ DESIG, 2010), sendo que, nos anos de 2006 e 2009, nada menos que $92 \%$ dos recursos investidos no setor se endereçaram para produção de etanol. ${ }^{5}$

${ }^{4}$ A perspectiva adotada neste trabalho não se vê representada na noção de biocombustíveis, uma vez que essa denominação traz consigo uma aceitabilidade social que vincula a produção de combustíveis agrícolas a uma matriz energética limpa e sustentável. Ao contrário disso, optou-se por utilizar a designação agrocombustíveis no intuito de enfocar a natureza agrícola, rural e territorial da produção desse insumo energético.

${ }^{5}$ Em 2007 e 2008, merece destaque o aumento expressivo dos investimentos estrangeiros diretos aplicados no setor, que saíram de US\$ 499,2 milhões em 2006, para US\$ 2 bilhões e 315 milhões em 2007 e US\$ 2 bilhões e 285 milhões em 2008. Quando se avaliam os países de procedência dos recursos nota-se que, no período, marcado pela crise financeira mundial, grande parte dos investimentos adveio de paraísos fiscais localizados no mar do Caribe. Ao se somarem os recursos originários das Bermudas, Ilhas Cayman, Ilhas Virgens e Ilhas do Canal Jersey, obtém-se a cifra de US\$ 2 bilhões e 273 milhões, valor que representa $66,2 \%$ dos investimentos estrangeiros no setor, do ano de 2007, e 44,6\% dos aplicados em 2008. Pode-se sugerir um entrecruzamento entre as crises financeira e climática 
A inserção nacional no mercado de agrocombustíveis elucida o funcionamento das novas relações centro-periferia e, nelas, o Brasil possui uma dupla função, ao mesmo tempo, neocolonial e imperialista; de um lado, representa o espaço de vazão dos capitais acumulados nas economias cêntricas (à disposição dos países que, por sua demanda de combustíveis, desejem reduzir suas emissões - os capitais são investidos através da atuação de conglomerados internacionais que exploram os recursos naturais e humanos, periferizando o território brasileiro em prol do abastecimento energético das economias cêntricas), função neocolonial; de outro, patrocina o alargamento da atuação das megacorporações nacionais, que, por sua vez, agem como cêntricas e periferizam territórios localizados na África e nos países centro-americanos, ampliando o mercado global de agrocombustíveis e possibilitando a inserção de novos territórios nos circuitos de acumulação, função imperialista. Os capitais e empresas brasileiras patrocinadas pela atuação do Estado se expandem na direção de oportunidades mais rentáveis de investimento.

Ao compreender a produção de agrocombustíveis como representativa de uma colonialidade na apropriação da natureza, pretende-se indicar a contínua importância dos recursos naturais para a manutenção da acumulação capitalista, bem como realçar a imprescindível expansão territorial que é levada a cabo, simultaneamente, por processos neocolonialistas e imperialistas. Para Lefebvre (1991), o modelo dual, que explicava o processo de acumulação com base na contradição entre capital e trabalho, se tornou incapaz de dar conta da crescente importância da natureza para a produção capitalista. Do mesmo modo, Veltz (1996), criticando uma economia ortodoxa, desligada da importância dos territórios e baseada em fluxos financeiros indiferentes aos lugares, afirma que há necessidade de se con-

através do qual se criam novos mercados, que, alavancados pelo discurso da preservação ambiental, transformam a degradacão do ar, água, solos e das populacões em novos circuitos de acumulação de capitais (BC/DESIG, 2010). siderar a relação entre economia e apropriação territorial, em que o território entra no jogo econômico como matriz de organização das interações econômico-sociais, e não somente como armazém ou conjunto de recursos técnicos e naturais. O território passa, portanto, a ser considerado como estrutura de organização das interações sociais e não mais como uma reserva de recursos sem passado ou futuro (Veltz, 1996, p. 15). Assim, reconhecer o papel da natureza no capitalismo expande e modifica os referenciais temporais e geográficos que marcaram e ainda marcam as narrativas da modernidade (Coronil, 2000).

Tratar a ocupação territorial da monocultura de cana para produção de agrocombustíveis como resultante de uma colonialidade na apropriação da natureza é uma tentativa de clarificar a permanência de um padrão de poder com traços colonialistas, que continuamente se revigora, se modifica e se reatualiza, buscando manter a exploração dos territórios. Nesse sentido, conceber a existência de uma colonialidade na apropriação da natureza é caminhar na direção de um projeto de descolonização simbólica e material que indaga as formas hegemônicas de usurpação das riquezas territorializadas que, por sua vez, sustentou e segue sustentando a continuidade da modernidade ocidental. É realçar, portanto, a força de um pensamento outro, calcado no ideal da descolonialidade, que aciona a diferença colonial irredutível para questionar os valores construídos como centrais (Khatibi, 2001).

Aqui se nomeia o terceiro termo do paradigma modernidade-colonialidade, que incorpora o potencial da ideia de descolonização e passa a ser reconhecido a partir da tríade modernidade-colonialidade-descolonialidade. Essa tríade analítica auxiliaria, portanto, na compreensão da transição do colonialismo moderno à colonialidade global, processo que certamente transformou as formas de dominação derivadas da modernidade, mas não modificou efetivamente a estrutura das relações centroperiferia em escala mundial (Castro-Gomez; 
Gosfroguel, 2007, p. 13) ${ }^{6}$. Nessa linha, a retomada das contribuições da teoria da dependência e da noção de centro-periferia pode clarificar o modo operativo da máquina de produção de desigualdades, que reproduz subalternidades sob a forma da colonialidade global vigente, hoje, nas sociedades interligadas.

Embora boa parte dos intelectuais que se orientaram pela teoria da dependência estivesse preocupada em compreender o que desviava os países periféricos dos trilhos do desenvolvimento, Cardoso e Faletto (1970) compreenderam a própria ambiguidade política do desenvolvimento e enxergaram como, em uma relação de dependência, os interesses internos se articulam com o restante do sistema capitalista. Desse modo, enfatizaram as tramas sociopolíticas que extrapolam uma explicação econômico-desenvolvimentista, que vê, nas relações externas, apenas oposições a supostos interesses nacionais globais, para reconhecer que, antes de uma oposição global, a dependência articula interesses de determinadas classes e grupos sociais da América Latina com os interesses de determinadas classes e grupos sociais de fora da América Latina (Oliveira, 2003). Para os objetivos deste artigo, interessa, portanto, reabilitar o conteúdo político da teoria da dependência no que tange à elu* cidação dos processos de subalternização dos స países periféricos à economia globalizada, bem como fazer transparecer a pertinência desse instrumental para a análise das dinâmicas espaciais contemporâneas expressas em complexos fluxos de mercadorias e finanças.

\section{POR UMA NOVA TEORIA DA DE- PENDÊNCIA: contemporaneidade das relações centro-periferia e reco- Ionização econômica}

Para Beigel (2006), em meados da década de 1990, a maioria dos cientistas sociais considerava a análise da dependência como

${ }^{6}$ Tradução de minha autoria do original em espanhol. uma perspectiva ultrapassada, desgastada pela globalização e inútil em um contexto de apagamento do Estado-nação. Ocorria, nessa época, uma reação contra a teoria, paradoxalmente no momento em que a subserviência política e econômica era reforçada pelo impacto da dívida externa e pela adesão aos preceitos do Consenso de Washington. Não obstante, Munck (1999), atento a esse contexto político-econômico dos anos 1990, afirmava que a dependência dos países latino-americanos ainda não havia desaparecido do mundo concreto e seguia bem viva, sendo alinhavada pelo receituário neoliberal, que mantinha a fé na convergência entre sociedades industriais avançadas e países atrasados, fornecedores de matérias-primas.

Do mesmo modo, Holloway (2003) sugere que, hoje mais do que nunca, cerca de 20 anos depois que saiu de moda entre as abordagens das ciências sociais, a teoria da dependência continua a fornecer um enquadramento útil para a compreensão da América Latina, uma vez que sua abordagem interpretativa e heurística permanece tendo o poder de nomear e explicar processos de subordinação econômica, política, cultural e ideológica. Assim, na atual fase da globalização econômica, torna-se ainda mais importante reafirmar e dar continuidade ao desenvolvimento das teorias sociais elaboradas no âmbito das nações periféricas. Nos dizeres de Kay (2009), isso não deveria ser interpretado de maneira estreita e chauvinista, mas, pelo contrário, como uma contribuição dos cientistas sociais latino-americanos a uma teoria crítica internacional de caráter mais holístico. ${ }^{7}$

Para além do contexto latino-americano, Amin (2005), retomando preceitos da teoria da dependência, argumenta que, em conjunto com a tríade-cêntrica composta por EUA, União Europeia e Japão, configuram-se hoje

${ }^{7}$ Para Ribeiro (2000), depois do fim da era da dependência, em algum momento da década de oitenta, a teoria social latino-americana não foi capaz de recuperar sua proeminência no cenário acadêmico internacional, com uma abordagem que fosse identificável com a região, apesar das brilhantes contribuições de inúmeros intelectuais. 
três estratos periféricos, a saber: o primeiro composto por China, os antigos países socialistas, Coréia do Sul, Taiwan, Índia, Brasil e México, que conseguiram construir sistemas produtivos nacionais (potencial ou realmente competitivos). Um segundo estrato, no qual se encontram os países árabes, África do Sul, Irã, Turquia e os outros países da America Latina, que ingressaram na industrialização, mas não conseguiram criar sistemas produtivos nacionais. Por fim, um terceiro estrato que engloba os países que ainda não entraram na revolução industrial e apenas alcançam competitividade nos domínios regulados pelas vantagens naturais, minas, petróleo e produtos agrícolas tropicais. Embora essa abordagem procure tornar complexo o quadro das relações centro-periferia, ainda mantém ênfase na lógica dos Estados-nação, bem como pressupõe estágios de desenvolvimento mediados pelo processo de industrialização, não realçando a complementaridade sistêmica entre nações industriais e fornecedoras de insumos básicos. Ademais, ignora o fluxo de capitais financeiros e de investimento direto que, oriundo do centro, busca valorização nos países periféricos, dando novos contornos às relações centro-periferia.

A permanência de análises como as de Amin (2005), que enfatizam tão somente o papel do Estado-nação na compreensão das relações centro-periferia, ${ }^{8}$ não captam o fato de que a globalização neoliberal tem provocado transformações profundas nas relações entre capital e trabalho, capital e recurso natural, e entre os capitais e os Estados nacionais. Essas transformações têm permitido um aumento da domina-

${ }^{8} \mathrm{O}$ Estado-nação, mesmo sendo uma das mais importantes instituições do capitalismo histórico, tornou-se um espaço limitado para compreensão das relações centro-periferia e de promoção das transformações políticas e sociais. Para Grosfoguel (2000), o enfoque clássico da teoria da dependência, ao não considerar as lutas sociais, acima e abaixo da estrutura dos estados nacionais, como espaços estratégicos de intervenção política, em parte devido à sua tendência de privilegiar o Estado como unidade de análise, acabou por comprometer a capacidade explicativa da teoria e acarretou consequências para o projeto político da esquerda latino-americana. Do mesmo modo, ao não enfocar as relações entre as corporações transnacionais e o desempenho do papel do Estado, deixou de iluminar, com maior precisão, as interferências e complementaridades resultantes desse relacionamento. ção do capital sobre a sociedade, sobre a natureza e sobre os níveis de regulação e interferência dos Estados Nacionais (Leiva, 2009). A esse respeito, Arrighi (1996) enfatiza que o aumento no número de empresas multinacionais e de transações, dentro delas e entre elas, tornou-se fator crucial e emblemático do definhamento do moderno sistema de nações territoriais, que era o lócus primário do poder. A isso se pode acrescentar o poderio resultante dos fluxos de capitais, que transitam cada vez mais rápidos e menos regulados pelos aparatos estatais.

Na perspectiva de Schwartzman (2006), a compreensão das relações de dependência tem sido reformulada à luz da teoria do sistema-mundo colonial-moderno. O termo dependência, que sempre implicou mais que pobreza ou efeitos prejudiciais da adoção de formas de organização exógenas, passou também a significar a pressão de agentes estrangeiros, por intermédio do mercado de capitais, com efeitos negativos tanto sobre as direções do desenvolvimento econômico nacional quanto sobre a soberania política e o bem-estar social da população. Sendo assim, a abordagem teórica deste trabalho procura contribuir para a retomada das discussões da teoria da dependência, bem como tenta iluminar a continuidade das relações centro-periferia, agora instituídas por intermédio da reconfiguração territorial e dos fluxos de capitais direcionados aos países da periferia do capitalismo. Essas novas relações centro-periferia estariam se estruturando por meio dos frequentes deslocamentos de capital e do avanço das grandes corporações transnacionais e conglomerados financeiros, que impõem novas formas organizativas de exploração do trabalho e dos recursos naturais territorializados.

Enquanto a teoria da dependência, formulada nas décadas de 1960 e 1970, enfatizava o papel dos Estados-Nacionais no exercício tanto da função cêntrica como da periférica, no atual momento histórico, seria mais prudente afirmar a existência de formas de dependência levadas a cabo pelo modo operativo das grandes corporações empresariais e conglomerados 
financeiros. O Estado e o mercado representariam, nesse esquema, dimensões complementares de um processo unitário que impulsiona a expansão do capitalismo por meio da perpetuação das relações centro-periferia. ${ }^{9}$ Se, antes, a posição de centro era exercida por uma dominação e uma influência política derivada do poder dos Estados, agora seria mais adequado conjeturar que as relações de dependência são resultado do poder econômico de grandes corporações transnacionais e conglomerados financeiros, que se ancoram na lógica de mercado e na influência política dos Estados de origem para fazer valer sua força de constrangimento.

No capitalismo atual, o econômico tem se emancipado da submissão ao político e se transformado na instância diretamente dominante que comanda a reprodução e evolução da sociedade (Amin, 2001). O processo de concentração e centralização dos capitais extrapola, assim, a esfera de controle dos Estados-nacionais e, por meio da ação das corporações transnacionais, expande a ocupação territorial do capital. Como destaca Oliveira (2007, p. 287) em sua análise das relações contemporâneas entre capitalismo e política:

A assimetria voltou numa escala que anula a política, isto é, a possibilidade de escapando a lógica de acumulação de capital, redistribuir o poder na sociedade de nosso tempo. Trata-se, agora, da anulação da política, da colonização da política pela economia.

Boaventura de Souza Santos (2010) nomeia esse processo como o exercício de governos indiretos, donde poderosos agentes não estatais adquirem o controle dos cuidados com

$\dot{\alpha}$ saúde e segurança, detêm a posse das terras, da água potável e das sementes, para, com base em obrigações contratuais privadas, promoverem a despolitização da sociedade. Como sugere Beigel (2006), tudo indica que, no cenário atual, é ainda mais oportuna a proposição dependentista de produzir um encontro teórico entre po-

${ }^{9}$ Para Amin (2003) a construção concomitante de centros dominantes e periferias dominadas e sua reprodução em cada etapa do sistema capitalista são próprias do processo de acumulação operante em escala global. lítica e economia, uma vez que ele se tornou o terreno onde se dá a verdadeira disputa.

Nesse contexto de esquecimento da política e de opulência da esfera econômica, ${ }^{10}$ marcado pela ampliação do poderio das corporações empresariais e conglomerados financeiros, argumenta-se, aqui, que as relações centro-periferia sofreram alterações, sendo hoje mais adequado vislumbrar a existência de um regime de dominação exercido por essas corporações de forma policêntrica e gerando multiperiferias. Assim, as novas relações centro-periferia não estariam mais vinculadas a posições geográficas estanques, expressas na figura dos Estados territoriais; ao contrário disso, derivariam da ação econômica de corporações transnacionais e conglomerados financeiros organizados em redes, estruturados territorialmente, apoiados por um Estado-nacional de origem, sendo policêntricos e engendrando multiperiferias. A posição de centro deixaria de ser exercida por um ou mais estados nacionais. Romper-se-ia, assim, com a perspectiva de uma relação centro-periferia geográfica, transitando para um centro-periferia ubíquo, levado a cabo por corporações transnacionais, compostas por capitais trasnfronteiriços que atuam em todas as partes do mundo. ${ }^{11}$

Para Hoogvelt (1997), à medida que o capital internacional se faz mais móvel e se separa de suas anteriores limitações institucionais, as relações centro-periferia vão se

${ }^{10}$ Nos dizeres de Paoli (2007), sobre a base de predominância da economia, se absorve o campo político para torná-lo um vasto oikos, no qual os governos se preocupam apenas com um crescimento econômico mal definido, enquanto os cidadãos se ocupam inteiramente de seu bem-estar material. Dito em outras palavras, a política se torna desnecessária na medida em que se nega a possibilidade de alternativas ao atual modelo de desenvolvimento.

11 As forças do mercado internacional dominam com um potencial ainda maior que no passado, e os estados nacionais têm de levá-las em maior consideração nos dias atuais, sob pena de terem de enfrentar grandes retiradas de capital externo, como ocorreu nos casos do México e da Argentina, respectivamente em 1994-1995 e 2001-2002 (Kay, 2009, p. 572). Para Boltanski e Chiapello (2009), o estabelecimento dessas novas formas de organização em rede torna as firmas muito mais flexíveis e muito menos frágeis do que as grandes empresas nacionais do passado. Assiste-se, assim, ao desenvolvimento de um capitalismo marcado pela preponderância de megacorporações empresariais, cada vez mais poderosas e autônomas em relação aos Estados, que se tornam cada vez mais fracos. 
convertendo em relações sociais, ao invés de se fixarem numa mera relação geográfica. No contexto das novas relações centro-periferia, marcadas pela dominância da esfera econômica e pelo poderio das corporações transnacionais e conglomerados financeiros, poderia se conjecturar, ecoando as afirmações de Coronil (2000), que o mercado se apresenta travestido e mascarado pela aparência de uma estrutura de possibilidades, que encobre sua fisionomia de regime de dominação, criando a ilusão de que a ação humana é livre e não limitada, a marginalização, o desemprego e a pobreza aparecem como falhas individuais e coletivas, quando deveriam ser vistas como efeitos inevitáveis de uma violência estrutural.

Nas palavras de Katz (2002), o correlato político dessa dominação econômica é uma recolonização da periferia, que se apoia na crescente associação das classes dominantes locais, com seus sócios do centro. Esse entrelaçamento tem como consequência a dependência financeira, a entrega dos recursos naturais e a privatização de setores estratégicos. A partir dessa imbricação de capitais, Robinson (2004) propõe ampliar a ideia de hegemonia para além de uma forma de dominação social inextricavelmente associada ao Estado. Ao contrário disso, sugere que grupos sociais e classes compostas no cenário das relações interestatais passam a exercer a hegemonia, operando de forma transnacional e utilizando outros arranjos e formas institucionais. Nessa abordagem, a hegemonia passa a ser exercida por uma classe capitalista transnacional que se constitui por intermédio da globalização dos fluxos financeiros e de mercadorias.

Essa forma de dominação do capital transnacional ocorre, portanto, quando os capitais nacionais expandem seu alcance para além das fronteiras e se fusionam com outros capitais nacionais já internacionalizados, dando origem a um processo transfronteiriço que os desincorpora da pertença à nação e os situa em um novo espaço supranacional, não mais orientado pela valorização estrita do capital de origem nacional (Robinson, 2004). O avanço transfronteiriço dos capitais tem desencadeado uma apropriação privada dos recursos naturais territorializados em países tidos como atrasados. Uma parte considerável desses recursos vem se transformando, quase que inevitavelmente, em propriedade privada de empresas transnacionais (Leiva, 2009). Embora os capitais também se direcionem para atividades industriais e tecnológicas, o montante principal tem sido investido em ramos atrelados ao complexo agro-minero-exportador.

Para se ter uma ideia desse processo, em 2008, ingressaram, no Brasil, US\$ 43,8 bilhões de dólares de investimento estrangeiro direto, sendo US\$ 12,9 bilhões destinados às atividades de agricultura, pecuária e extrativa mineral, outros US\$ 6,7 bilhões para metalurgia e fabricação de coque, derivados de petróleo e bicombustíveis, e mais US\$ 5,7 bilhões em investimentos diretos em atividades do serviço financeiro. Assim, o ramo extrativo e de apropriação de recursos naturais somado aos investimentos diretos em atividades do setor financeiro, totalizaram US\$ 25,3 bilhões de dólares, representando 57,8 \% de todos os investimentos diretos aplicados no país. Por outro lado, ao se somarem os investimentos na fabricação de equipamentos de informática, produtos eletroeletrônicos e ópticos, na fabricação de máquinas, aparelhos e materiais elétricos e na produção de máquinas e equipamentos diversos, obtêm-se US\$ 986,6 milhões de dólares, que, expressos de outra forma, representam 2,2 \% dos investimentos estrangeiros diretos (BC/DIFIS, 2009).

Ao analisar esses fluxos financeiros da economia global, Patnaik (2005) visualiza um processo de acumulação de capitais que denomina acumulação por meio da invasão, donde certos blocos de capital crescem através do deslocamento (o que significa expropriação ou compra a preços descartáveis) de outros blocos, expandem-se por meio do despojamento de formas pré-capitalistas de produção ou de setores comandados pelo Estado, bem como através da apropriação de recursos comuns 
que não formavam parte da propriedade privada. Como boa parte dos investimentos diretos de capital externo, associados ou não ao capital nacional, destina-se à exploração e apropriação de recursos naturais, isso tem impactado negativamente os modos de vida e as formas de reprodução social de inúmeros grupos que são subalternizados pela lógica excludente da acumulação de capitais.

Ainda que, no contexto atual, o comércio intersetorial de manufaturas e produtos básicos já não defina as relações centro-periferia, haja vista a instalação de indústrias transnacionais nos países tidos como atrasados, como se pôde notar no exemplo brasileiro da produção de agrocombustíveis, um grande percentual dos investimentos estrangeiros tem se destinado à apropriação privada de recursos naturais e territórios. Para Di Filippo (1998), a tendência de mudança, impulsionada pela migração de empresas multinacionais para a periferia, está clausurando as formas intersetoriais de comércio que caracterizavam o paradigma centro-periferia, onde o centro fornecia produtos manufaturados e a periferia produtos básicos. Essa forma de intercâmbio estaria sendo substituída pelo comércio intraindustrial e intrafirmas,

Gráfico 1: Exportações brasileiras por tipo de produto - 1970-2010

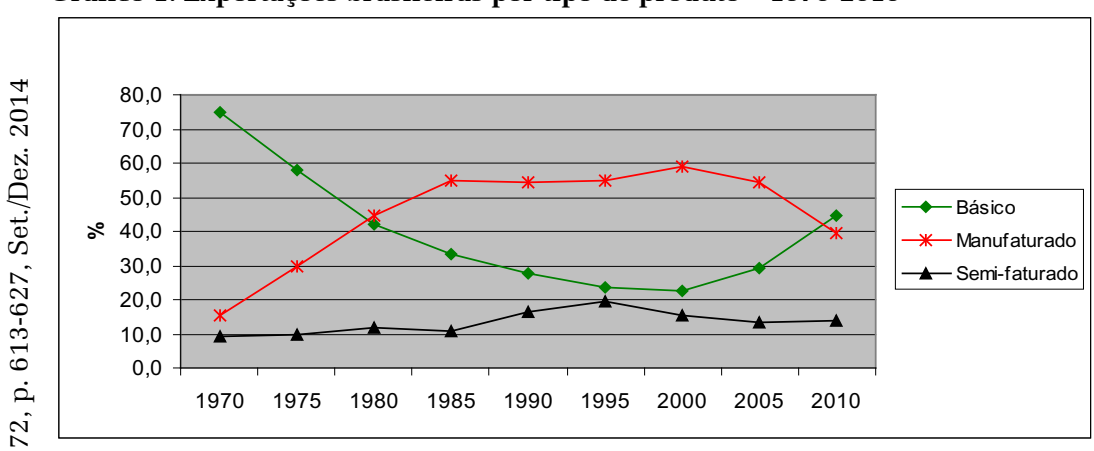

Fi Fonte: MDIC/DEPLA, c2011.

com as corporações transnacionais produzindo bens manufaturados na periferia e exportando para as economias cêntricas. Entretanto, os dados brasileiros de comércio exterior, ilustrados no gráfico disposto a seguir, sugerem uma inversão na pauta de exportações a partir do ano 2000 , com os produtos manufaturados perden- do força e os básicos crescendo em relevância.

Ao se relacionar os dados do gráfico com os valores de investimento estrangeiro direto apresentados anteriormente, constata-se que o ingresso de capitais na apropriação privada e exploração de recursos naturais tem resultado em um crescimento das exportações de produtos primários; dito de outro modo, é plausível sugerir uma vinculação entre a extração de riquezas naturais, a exportação de produtos primários e a valorização dos capitais que aportam no Brasil. Para Coronil (2000), a globalização neoliberal tem homogeneizado e feito abstratas diversas formas de riqueza, incluindo a natureza, que vem se convertendo, para muitos países, em sua vantagem comparativa mais segura e sua fonte principal de ingresso ${ }^{12}$.

Esse exemplo da relação entre exportação de produtos básicos e ingresso de investimento estrangeiro direto clarifica o fato de que a acumulação capitalista está fundamentalmente enraizada na tríade; apropriação de sistemas ecológicos, exploração do trabalho e valorização financeira. Nota-se, portanto, que a inserção brasileira na economia global tem se processado através da dilapidação do patrimônio natural, da degradação e contaminação do meio ambiente, da exploração de mão de obra barata ou em regime de escravidão, da expropriação de populações camponesas e da subserviência aos mecanismos de valorização financeira. Agregue-se a isso o fato de que os princípios de conservação e preservação ambiental que já foram impostos às corporações

${ }^{12}$ Em artigo publicado no Le Monde Diplomatique, o Subcomandante Marcos argumenta que a globalização moderna e o neoliberalismo como sistema mundial devem ser reconhecidos como uma nova guerra de conquista de territórios. Nessa nova guerra, a política, como organizadora do Estado-nacional, não existe mais, foi tragada pela esfera econômica, e os políticos se transformaram em modernos administradores de empresas interessados em gerir os negócios estatais como se estivessem à frente de lojas de departamentos (Marcos, 1997). 
industriais pelos governos dos países centrais, a fim de racionalizar a utilização dos recursos naturais, nunca são aplicados na mesma medida em países periféricos, onde o imperialismo ecológico abertamente vem impondo suas marcas (Clark; Foster, 2009). ${ }^{13}$

A regressão primário-exportadora atualmente verificada no Brasil, em associação com a entrada de investimento estrangeiro direto no controle e apropriação de recursos naturais, são amostras da continuidade de um processo dotado de raízes estruturais, assim como da pertinência de uma análise calcada nos pressupostos da teoria da dependência. Schwartzman (2006) vai mais longe e afirma que as relações de dependência consolidadas através dos fluxos de capitais têm ameaçado afetar até mesmo a legitimidade da democracia brasileira. Para a autora, a adoção, na última década, do paradigma do liberalismo por parte dos governos brasileiros, embora componha as diretrizes da nova globalização, não alteraram os fundamentos do processo, ou seja, no interior das relações entre nações "desenvolvidas" e "em desenvolvimento", ainda persiste o componente da dependência. A esse respeito, a reprimarização da economia, que tem vigorado nos países latino-americanos, pode ser considerada como um indicativo da continuidade das relações de dependência e um retorno às formas de controle colonial baseadas na explo-

${ }^{13}$ Clark e Foster (2009) caracterizam o imperialismo ecológico como algo que cria assimetrias na exploração do meio ambiente, impulsiona a troca desigual e provoca uma ruptura metabólica global, agravando a subordinação das nações periféricas. Nesse cenário, os acordos internacionais de comércio, influenciados pela dinâmica da economia global e pelas posições dentro do sistema-mundo, afetam e impactam negativamente as condições socioecológicas dos países extrativistas e periféricos. Na avaliação de Hornborg (1997), não é possível compreender a acumulação, o desenvolvimento ou a moderna tecnologia ocidental, sem se referir a esse intercâmbio comercial entre nações e o modo como os valores de troca se relacionam à termodinâmica. Para o autor, uma junção entre economia ecológica e leis da física possibilita compreender a maneira através da qual as instituições de mercado organizam a transferência líquida de energia e materiais para os centros do sistema. De acordo com esse raciocínio, os preços de mercado e a troca desigual são mecanismos arbitrários por meio dos quais as economias centrais do sistema-mundo extraem energia e exportam entropia para suas periferias. Nesse sentido, o intercâmbio desigual vigente no sistema-mundo colonial-moderno reproduz as máquinas e essas, por sua vez, reproduzem o intercâmbio desigual. ração de produtos primários e de força de trabalho barata (Coronil, 2000, p. 99).

No momento atual, em que talvez a característica mais importante da nova fase do imperialismo seja a abertura comercial e o aperto territorial que se impõe à economia rural dos países tidos como atrasados (Patnaik, 2005), a junção entre imperialismo, teoria da dependência, relações centro-periferia e paradigma modernidade-colonialidade pode ser útil na compreensão das dinâmicas de reconfiguração territorial impostas ao meio rural brasileiro, bem como ajuda a clarificar as formas de inserção da produção de commodities na economia mundial. Ao remontar às raízes históricas, epistêmicas, político-econômicas, culturais e ideológicas que interligam os territórios latino-americanos, sobretudo o brasileiro, às lógicas operativas do capitalismo transnacional, o presente artigo intentou construir uma perspectiva teórico-metodológica, que permita iluminar o cenário atual de inserção de novos territórios nos circuitos de acumulação do capital. A linha de raciocínio aqui trilhada ambicionou realçar que o estudo de uma frente atual de expansão do capitalismo permite a análise concreta de um processo que reproduz, em algumas de suas linhas mais gerais, uma etapa da própria formação histórica do Brasil, na medida em que as atuais frentes podem ser consideradas, de certa maneira, como as continuadoras do processo histórico de expansão e colonização territorial (Velho, 1972).

\section{REFLEXÕES FINAIS}

Duas coisas bem distintas / Uma é o preço, outra é o valor / Quem não entende a diferença / Pouco saberá do amor, da vida, da dor, da glória / E tampouco dessa história / Memória de cantador [... ] E até o velho Chico cantou pra todo mundo ouvir: Hay que, hay que, eike, hay que, hay que, hay que resistir!
El Efecto. Música $O$ Encontro de Lampião com Eike Batista, 2012

Ao lançar mão da ideia de que há uma colonialidade na apropriação da natureza, entendida tanto como resultado da construção no interior da modernidade de formas econômico 
-instrumentais de se pensar e explorar o meio ambiente quanto como expressão de processos de expropriação territorial que sustentam a lógica prevalecente da acumulação capitalista, procurou-se elucidar o papel da episteme na legitimação da expansão territorial e dos deslocamentos da lógica de acumulação. A produção de um conhecimento silenciador de outras realidades e de modos distintos de uso, significação e apropriação da natureza representa, assim, uma arma importante na justificação de processos expropriatórios que continuamente têm promovido a rapina dos recursos territorializados nos países periferizados. A colonialidade na apropriação da natureza é vista, portanto, como expressão de novos mecanismos de poder, que se traduzem na existência de formas hegemônicas de se conceber e explorar os recursos naturais, considerando-os unicamente como mercadorias, ao mesmo tempo em que evidencia o aniquilamento de modos subalternos de convívio com o meio ambiente, bem como a perpetuação e justificação de formas assimétricas de apropriação dos territórios.

Ao retomar as discussões da teoria da dependência, visando a analisar as dinâmicas de avanço do capitalismo, tentou-se iluminar a continuidade das relações centro-periferia que estariam se estruturando por meio dos frequentes deslocamentos de capital e do avanço das grandes corporações transnacionais e conglomerados financeiros, que impõem novas formas organizativas de exploração do traba- lho e dos recursos naturais territorializados. Enquanto a teoria da dependência, formulada nas décadas de 1960 e 1970, enfatizava o papel i dos Estados-nacionais no exercício, tanto da \& função cêntrica como periférica, no atual moస mento histórico, seria mais prudente afirmar a $\vec{*}$ existência de formas de dependência levadas a cabo pelo modo operativo das grandes corporações empresariais e conglomerados financeiros. O Estado e o mercado representariam, nesse esquema, dimensões complementares de um processo unitário que impulsiona a expansão do capitalismo por meio da perpetua- ção das relações centro-periferia.

Por último, mas não menos importante, vale destacar que este trabalho foi sendo construído ao modo de quem monta um quebra-cabeça, cujas peças pertencem a diferentes figuras. Assim, mesclando-se cores, matizes, tradições intelectuais, tempos e perspectivas, procurou-se iluminar a contínua inserção de novos territórios nos circuitos de acumulação do capital. Ainda que algumas peças desse quebra-cabeça tenham sido encaixadas sem muita perfeição, quase empurradas por uma curiosidade que ainda desconhece as feições da totalidade, espera-se, à maneira do que sugere Coronil (2003), que esse encaixe imperfeito, essa figuração derivada do equívoco, permita vislumbrar algo não imaginado antes, de modo que aquilo que ainda não se encaixa corretamente possa oferecer uma inesperada iluminação.

Recebido para publicação em 03 de julho de 2013 Aceito em 28 de setembro de 2013

\section{REFERÊNCIAS}

AMIN,Samir.Geopolítica delimperialismocontemporáneo. In: BORON, Atilio A. (comp.). Nueva hegemonía mundial: alternativas de cambio y movimientos sociales. Buenos Aires: CLACSO, Consejo Latinoamericano de Ciencias Sociales, 2003.

Capitalismo, imperialismo, mundialización. In: SEOANE, José; TADDEI, Emilio. (Comp.) Resistencias mundiales. Buenos Aires: CLACSO; 2001.

O imperialismo, passado e presente. Tempo. Niterói, v. 9, n. 18, p. 77-123, jun. 2005. Disponível em http:/www.scielo.br/scielo.php?script=sci arttext\&pid=S1413-77042005000100005. Acesso em: 11 abr. 2011.

APPADURAI, Arjun. La modernidad desbordada Tradução: Gustavo Remedi. México: Ediciones Trilce, Fondo de Cultura Econômica, 2001.

ARRIGHI, Giovanni. O longo século XX: dinheiro, poder e as origens de nosso tempo. Rio de Janeiro: Contraponto, 1996.

BANCO CENTRAL. DIRETORIA DE FISCALIZAÇÃO Investimentos Estrangeiros Diretos: Tabelas - Censos 1995/2000 e ingressos 2001 a 2006. Brasília, DF: DIFIS, 2009. Disponível em: http://www.bcb.gov.br/rex/ied/port/ ingressos/htms/index2.asp?idpai=INVEDIR. Acesso em 12 out. 2010 .

Departamento de Monitoramento do Sistema Financeiro e Gestão da Informacão. Estoque de investimento estrangeiro direto. Brasília, DF: BC/DESIG, 
2010. Disponível em: http://www.bcb.gov.br/rex/ied/port/ ingressos/htms/index2.asp?idpai=INVEDIR. Acesso em 14 out 2010 .

BEIGEL, Fernanda. Vida, muerte y resurrección de las teorías de la dependencia. In: et. al. Crítica y teoría en el pensamiento social latinoamericano. Buenos Aires: CLACSO, 2006.

BOLTANSKI, Luc; CHIAPELLO, Ève. O novo espírito do capitalismo. São Paulo: Wmf Martins Fontes, 2009.

CAJIGAS-ROTUNDO, Juan Camilo. La biocolonialidad del poder. Amazonía, biodiversidad y ecocapitalismo. In: CASTRO-GOMEZ, Santiago; GOSFROGUEL, Ramón (comp). El Giro Decolonial: reflexiones para una diversidad epistémica más allá del capitalismo global. Bogotá Universidad Javeriana-Instituto Pensar, Universidad Central-IESCO, Siglo del Hombre, 2007.

CARDOSO, Fernando Henrique; FALETTO, Enzo. Dependência e desenvolvimento na America Latina: ensaio de interpretação sociológica. 7.ed. Rio de Janeiro: LTC, 1970

CASTRO-GÓMEZ, Santiago. Decolonizar la Universidad: La hybris del punto cero y el diálogo de saberes”,.In: CASTRO-GOMEZ, Santiago; GOSFROGUEL Ramón (Comp). El giro decolonial: reflexiones para una diversidad epistémica más allá del capitalismo global. Bogotá Universidad Javeriana-Instituto Pensar, Universidad Central-IESCO, Siglo del Hombre, 2007. p. 79-91

Ciencias sociales, violencia epistémica y el problema de la invención del otro. In: LANDER, Edgardo (Comp.). La colonialidad del saber: eurocentrismo y ciencias sociales. Perspectivas Latinoamericanas. Buenos Aires: CLACSO, Consejo Latinoamericano de Ciencias Sociales, 2000

CASTRO-GÓMEZ, Santiago; GROSFOGUEL, Ramón. Prólogo: giro decolonial, teoría crítica y pensamiento heterárquico. In: CASTRO-GOMEZ, Santiago GOSFROGUEL, Ramón (comp). El Giro Decolonial: reflexiones para una diversidad epistémica más allá del capitalismo global. Bogotá: Universidad JaverianaInstituto Pensar, Universidad Central-IESCO, Siglo de Hombre, 2007.

CHAKRABARTY, Dipesh. Provincializing Europe: postcolonial thought and historical difference. Nova Jersey: Princeton University Press, 2000

CLARK, Brett; FOSTER, John Bellamy, Ecologica Imperialism and the Global Metabolic Rift. Internationa Journal of Comparative Sociology, Toronto, n. 50, p. 311334,2009 ,

CORONIL, Fernando. Naturaleza del poscolonialismo: del eurocentrismo ao globocentrismo. In: LANDER, Edgar. (Org). La colonialidad del saber: eurocentrismo y ciencias sociales, Buenos Aires, CLACSO, 2000.

El Estado de América Latina y sus Estados: Siete piezas para un rompecabezas por armar en tiempos de izquierda. In. Nueva Sociedad, Caracas, No. 210, pp. 203215, 2007

El Estado mágico. Naturaleza, dinero y modernidad en Venezuela, Introducción, Consejo de Desarrollo Científico y Humanístico de la Universidad Central de Venezuela. In. Nueva Sociedad, Venezuela, 2002, p. 1-20

¿Globalización Liberal o Imperialismo Global? Cinco Piezas para Armar el Rompecabezas del Presente. Revista Temas, Lisboa, n. 33-34, p. 14-27, abr./-sep., 2003.

DI FILIPPO, Armando. La visión centro-periferia hoy. Revista de la CEPAL,Santiago de Chile, Número extraordinario, p. 175-185, oct. 1998.

ESCOBAR, Arturo. Mundos y conocimientod de otro modo: el programa de investigación de modernidad/ colonialidad latinoamericano. Tabula Rasa
Bogotá, n. 1, p.51-86, enero-diciembre, 2003.

El Lugar de La Naturaleza y La Naturaleza del Lugar: globalización o postdesarrollo? In. LADER, E. (Org.) La Colonialidad del Saber: eurocentrismo y ciencias sociales, perspectivas latinoamericanas. La Habana: Editorial de Ciencias Sociales, 2005, p. 115-152.

ELIAS, Norbert. O processo civilizador. Rio de Janeiro: Jorge Zahar, 1994. 2 v

GARCÉS, Fernando. Las políticas del conocimiento y la colonialidad lingüística y epistémica. In: CASTROGOMEZ, Santiago; GOSFROGUEL, Ramón (Comp) El Giro Decolonial: reflexiones para una diversidad epistémica más allá del capitalismo global. Bogotá: Universidad Javeriana-Instituto Pensar, Universidad Central-IESCO, Siglo del Hombre, 2007

GROSFOGUEL, Ramón. Developmentalism, modernity, and dependency theory in Latin America. Nepantla: views from south, Parkville, n. 1/2, p. 347-76, 2000.

GUHA, Ranajit. Dominance without hegemony: history and power in colonial india. Cambridge: Cambridge University Press, 1997.

HALE, Charles. Does multiculturalism menace? governance, cultural rights and the politics of identity in Guatemala. Journal of Latin American Studies, Cambridge, v. 34, p. 485-524, 2002.

HOLLOWAY, Thomas. The Persistence of 'Dependency' as a Useful Framework for Understanding Latin America. H-Net Reviews: humanities \& social sciences, East Lansing, Michigan, 2003. Disponivel em: http://www.hnet.org/ latam/essays/dependency.pdf. Acesso em: 12 jul. 2011

HOOGVELT, Ankie. Globalization and the postcolonial world: the new political economy of development. Baltimore: Johns Hopkins University Press, 1997

KATZ, Claudio. El imperialismo del siglo XXI. Jun. 2002. Disponível em: www.eltabloid.com/claudiokatz. Acesso em: 18 mar. 2010 .

KAY, Cristobál. Teorias estruturalistas e teoria da dependência na era da globalização. In: MARTINS, Carlos Eduardo; SOTELO VALENCIA, Adrian (Org.). A América Latina e os desafios da globalização: ensaios dedicados a Ruy Mauro Marini. São Paulo: Boitempo, 2009.

KHATIBI Abdelkebir, Maghreb plural. In: MIGNOLO, Walter. (comp). Capitalismo y geopolítica del conocimiento: el eurocentrismo y la filosofía de la liberación en el debate intelectual contemporáneo. Buenos Aires: Ediciones del Signo, 2001

LANDER, Edgardo. Marxismo, eurocentrismo y, colonialismo. In: BORON, Atilio; AMADEO, Javier; GONZÁLEZ, Sabrina (Comp.). La teoría marxista hoy: problemas y perspectivas, Buenos Aires: CLACSO, 2006.

Ciencias sociales: saberes coloniales y eurocéntricos. In: Edgardo Lander (comp.) La colonialidad del saber: eurocentrismo y ciencias sociales. Perspectivas Latinoamericanas. CLACSO, Consejo Latinoamericano de Ciencias Sociales, Buenos Aires, 2000.

LATOUR, Bruno. Jamais fomos modernos: ensaio de antropologia simétrica. Rio de Janeiro: Editora 34, 1994.

LEFEBVRE, Henri. The production of space. Oxford, U.K. Blackwell, 1991. 454 p.

LEIVA, Orlando Caputo. A economia mundial e a América Latina no início do século XXI. In: MARTINS, Carlos Eduardo; SOTELO VALENCIA, Adrian (Org.). A América Latina e os desafios da globalização: ensaios dedicados a Ruy Mauro Marini. São Paulo: Boitempo, 2009

MALDONADO-TORRES, Nelson. Sobre la colonialidad del ser, contribuciones al desarrollo de un concepto. In: 
CASTRO-GOMEZ, Santiago; GOSFROGUEL, Ramón (Comp). El giro decolonial: reflexiones para una diversidad epistémica más allá del capitalismo global. Bogotá Universidad Javeriana-Instituto Pensar, Universidad Central-IESCO, Siglo del Hombre, 2007. P. 127-167.

MARCOS, Subcomandante Insurgente. Siete piezas sueltas del rompecabezas mundial: El neoliberalismo como rompecabezas: la inútil unidad mundial que fragmenta y destruye naciones. Revista Chiapas, México DF, n. 5,1997. Disponível em: http://www.revistachiapas. org/No5/ch5.html. Acesso em: 12 out. 2010.

MINISTÉRIO DO DESENVOLVIMENTO, INDÚSTRIA E COMÉRCIO EXTERIOR - MDIC. Sistema de Análise das Informações de Comércio Exterior via Internet (ALICEWeb). Brasilia, DF: Departamento de Planejamento e Desenvolvimento do Comércio Exterior. Secretaria de Comércio Exterior, MDIC, c2010. Disponível em: http:/ aliceweb.desenvolvimento.gov.br. Acesso em: 22 abr. 2010

Departamento de Planejamento e Desenvolvimento do Comércio Exterior. Estatísticas de Comércio Exterior. Brasília, DF: Departamento de Planejamento e Desenvolvimento do Comércio Exterior. Secretaria de Comércio Exterior, MDIC, c2011. Disponível em: http://www. mdic.gov.br/sitio/interna/interna.php?area $=5 \&$ menu $=1906$ Acesso em: 14 out. 2011

MIGNOLO, Walter. Histórias locais / projetos globais colonialidade, saberes subalternos e pensamento liminar. Belo Horizonte: Editora UFMG, 2003a.

MUNCK, Ronaldo. Dependency and imperialism in the new times: A Latin American perspective.The European Journal of Development Research, London,v. 11, n. 1, p. 56-74, 1999.

OLIVEIRA, Francisco de. Crítica à razão dualista: o ornitorrinco. São Paulo: Boitempo, 2003.

Capitalismo e política: um paradoxo letal. In: NOVAES, Adauto. O esquecimento da política. Rio de Janeiro: Agir, 2007

PAOLI, Maria Célia. O mundo do Indistinto: Sobre gestão, violência e política. In: OLIVEIRA, Francisco de; RIZEK, Cibele Saliba. A era da indeterminação. São Paulo: Boitempo, 2007.

PATNAIK, Prabhat. The Economics of the New Phase of Imperialism". Paper presented to the International Conference Acts of Resistance from the South against Globalization,Ankara, 5-7 September 2005.

官

QUIJANO, Aníbal. Colonialidad del Poder, Cultura y Conocimiento en América Latina. In: Anuário ช Mariateguiano. Lima: Amatua, v. 9, n. 9, 1997

(1)

. Don Quijote y los molinos de viento en América

Latina. Revista Electrónica de Estudios Latinoamericanos, N Buenos Aires, v. 4, n. 14, enero/marzo 2005.

; WALLERSTEIN, Immanuel. Americanity as a concept or the Americas in the modern world-system. i. Internat

i

$\curvearrowright$ RANCIÈRE, Jacques. Hatred of democracy. London: Verso,

வ் 2006 .

ลิ RIBEIRO, Gustavo Lins. Post-Imperialismo: para $>$ una discusión después del post-colonialismo y del multiculturalismo. In: Mato, Daniel (Coord.). Estudios latinoamericanos sobre cultura y transformaciones sociales en tiempos de globalización. Buenos Aires: Clacso-Asdi, 2000.

ROBINSON, William I. What empire? Whose hegemony? The transnationalization of capital and the gramscian critique of "statolatry" In: ANNUAL CONFERENCE OF INTERNATIONAL STUDIES ASSOCIATION, Montreal, mar. 2004.

SANTOS, Boaventura de Sousa. O Oriente entre Diferenças e Desencontros. Notícias do Milênio. Diário de Notícias, 8-7- pp. 44-51, 1999

Para uma sociologia das ausências e uma sociologia das emergências. In: SANTOS, Boaventura de Sousa (Org.). Conhecimento prudente para uma vida decente: um discurso sobre ciências revisitado. São Paulo: Cortez, 2003. pp. 777-821.

Para além do pensamento abissal. In: SANTOS, Boaventura de Sousa; MENESES, Maria Paula. Epistemologias do Sul. São Paulo: Cortez, 2010.

SCHWARTZMAN, Kathleen. Globalization from a worldsystem perspective: a new phase in the core-a new destiny for Brazil and the semiperiphery?. Journal of World Systems Research, Washington, DC, v. 12, n. 2, p. 265-3-7,december 2006.

SILVA, Luiz Inácio Lula da. Discurso durante encerramento do Seminário Empresarial Brasil-Zâmbia. In: SEMINÁRIO EMPRESARIAL BRASIL-ZÂMBIA, 8 jul. 2010, Lusaca, Zâmbia. Discurso de encerramento. Lusaca, Zâmbia; Brasília, DF: Ministério das Relações Exteriores, Assessoria de Imprensa do gabinete, 2010. Disponível em:

<http://kitplone.itamaraty.gov.br/sala-de-imprensa/ discursos-artigos-entrevistas-e-outras-comunicacoes/ presidente-da-republica-federativa-do-brasil/discursodurante-encerramento-do-seminario-empresarial-brasilzambia/print-nota >. Acesso em: em 12 abr. 2011

SPIVAK, Gayatri Chakravorty. Pode o Subalterno Falar?. Belo Horizonte: UFMG, 2010.

STENGERS, Isabelle; PIGNARRE, Philippe. La sorcellerie capitaliste: pratiques de désenvoûtement. Paris: De'couverte, 2005.

VELHO, Otavio Guilherme. Frentes de expansão e estrutura agrária: estudo do processo de penetração numa área da Transamazônica. Rio de Janeiro: 1972.

VELTZ, Pierre. Mundialización, ciudades y territórios. Barcelona: Editorial Ariel, 1996.

VISVANATHAN, Shiv. Convite para uma guerra da ciência. In: SANTOS, Boaventura de Sousa (Org.). Conhecimento prudente para uma vida decente. São Paulo: Cortez, 2004 p. 757-776.

WALSH, Catherine; SCHIWY, Freya; CASTRO-GÓMEZ, Santiago (Editores). Indisciplinar las ciencias sociales: geopolíticas del conocimiento y colonialidad del poder: perspectivas desde lo andino. Quito: Abyala, 2002.

WALSH, Catherine. Las geopolíticas del conocimiento y colonialidad del poder: entrevista a Walter Mignolo. Polis: Revista de la Universidad Bolivariana [On-line], Chile, v. 1, n. 4, 2003b. Disponível em:http://www.redalyc.org/ articulo.oa?id=30500409. Acesso em: 22 abr. 2010 


\section{FROM COLONIALISM TO COLONIALITY: territorial expropriation on the outskirts of capitalism}

\author{
Wendell Ficher Teixeira Assis
}

This article is based on the formulations of LatinAmerican authors who study the paradigm modernity-coloniality. They suggest that the processes of territorial expansion were, and still are, fundamental for the capitalist logic. If in historic colonialism the plunder of natural resources was done through strength and political-military supremacy of the colonizer State, currently other mechanisms of power guarantee the continuity of the exploration. In order to elucidate this process, the notion of coloniality in the appropriation of nature is formulated, understood as a result of the constructions in the interior of modernity which think of economic-instrumental ways of exploring the environment. Lastly, we go back to discussions regarding the pertinence of the theory of dependence and based on empirical data, suggest the emergence of new downtown-outskirts relations which would be structured by the constant displacement of capitals and by the way big international corporations impose new organized ways of exploring work and nature.

Keywords: Coloniality. Colonialism. Downtownoutskirts. Territorial Expropriation. Theory of dependence.

\section{DU COLONIALISME À LA COLONIALITÉ: expropriation territoriale dans la périphérie du capitalisme}

\author{
Wendell Ficher Teixeira Assis
}

Larticle se base sur les formules des auteurs latino-américains regroupés autour du paradigme modernité-colonialité pour suggérer que les processus d'expansion territoriale ont été et sont toujours nodaux dans la logique capitaliste. Si, dans le colonialisme historique, le pillage des ressources naturelles était justifié par la force et la suprématie politique et militaire de l'État colonisateur, actuellement d'autres mécanismes de pouvoir sont en place pour garantir la continuité de l'expropriation. Pour élucider ce processus, une nouvelle formule est apparue, celle de la colonialité dans l'appropriation de la nature, étimée comme résultat de la construction au sein de la modernité de moyens économiques et instrumentaux de penser et d'exploiter l'environnement. Pour finir, on reprend les discussions sur la pertinence de la théorie de la dépendance et, en se basant sur des données empiriques, on signale le surgissement de nouvelles relations centre-périphérie qui seraient en train de s'établir sur des mouvements fréquents de capitaux et sur la manière qu'ont les grandes corporations transnationales d'imposer de nouvelles formes d'organisation de l'exploitation du travail et de la nature.

Mots-ClÉs: Colonialité. Colonialisme. Centrepériphérie. Expropriation Territoriale. Théorie de La dépendance.

Wendell Ficher Teixeira Assis - Doutor em Planejamento Urbano e Regional. Professor Adjunto da Universidade Federal de Alagoas. Pesquisador do ETTERN/IPPUR da Universidade Federal do Rio de Janeiro. Tem experiência na área de Sociologia, com ênfase em Sociologia e Meio Ambiente. Atuando principalmente nos seguintes temas:Agrocombustíveis, Monocultura de Cana-de-Açúcar, Conflitos Ambientais. Publicações recentes: O moderno arcaísmo nacional: Investimento estrangeiro direto e expropriação territorial no agronegócio canavieiro. Revista de Economia e Sociologia Rural (Impresso), v. 52, p. 285-302, 2014; As novas Terras do Sem-fim: Expansão capitalista e acumulação primitiva no Brasil rural. Campo - Território, v. 14, p. 212-242, 2014; Desregulación, conflictos territoriales y movimientos de resistencia: la minería en la Amazonía brasileña. Letras Verdes, v. 14, p. 117-138, 2013. 
